Original

\title{
Effect of sodium sulfite, carboxylic monomer, and phosphoric acid etching on bonding of tri- $n$-butylborane initiated resin to human enamel
}

\author{
Hiroshi Nogawa1), Hiroyasu Koizumi ${ }^{2,3)}$, Nobutaka Akazawa1), Haruto Hiraba1), \\ Mitsuo Nakamura'), and Hideo Matsumura ${ }^{2,3)}$ \\ 1)Division of Applied Oral Science, Nihon University Graduate School of Dentistry, Tokyo, Japan \\ 2)Department of Fixed Prosthodontics, Nihon University School of Dentistry, Tokyo, Japan \\ 3)Division of Advanced Dental Treatment, Dental Research Center, Nihon University School of Dentistry, \\ Tokyo, Japan
}

(Received November 17, 2014; Accepted January 17, 2015)

\begin{abstract}
The purpose of the present study is evaluation of bonding durability of tri- $n$-butylborane (TBB) initiated resin without 4-methacryloyloxyethyl trimellitate anhydride (4-META) joined to human enamel. Ground human enamel was bonded with TBB resin under six surface conditions: 1) as ground, 2) primed with Teeth Primer, 3) sodium sulfite solution, 4) 4-META solution, 5) acetone-water, and 6) phosphoric acid etching. Pre- and post-thermocycling bond strengths and change in strength after thermocycling were compared. Etching enamel with $35-45 \%$ phosphoric acid enhanced bonding durability between enamel and TBB-initiated resin. Priming with Teeth Primer or 4-META solution improved bond strength between enamel and TBB-initiated resin. Sodium sulfite had little effect on enamel bonding in the present bonding systems. (J Oral Sci 57, 17-24, 2015)
\end{abstract}

Keywords: anhydride; enamel; etching; phosphoric acid; sodium sulfite; tri- $n$-butylborane.

\footnotetext{
Correspondence to Dr. Hiroyasu Koizumi, Department of Fixed Prosthodontics, Nihon University School of Dentistry, 1-8-13 Kanda-Surugadai, Chiyoda-ku, Tokyo 101-8310, Japan Fax: +81-3-3219-8351 E-mail: koizumi.hiroyasu@nihon-u.ac.jp doi.org/10.2334/josnusd.57.17 DN/JST.JSTAGE/josnusd/57.17
}

\section{Introduction}

Application of tri- $n$-butylborane (TBB) initiated adhesive resin for bonding of dental prostheses has increased substantially during the past two decades. TBB initiated methyl methacrylate (MMA) resins have been used for bonding enamel (1-4), dentin $(3,5)$, casting alloy $(6-8)$, and ceramics (9-11) in combination with various etchants and primers.

The bonding performance of a self-etching primer containing 4-methacryloyloxyethyl trimellitate anhydride (4-META) and sodium sulfite (Teeth Primer, Sun Medical Co. Ltd., Moriyama, Japan) was previously evaluated in vitro using primary and permanent human enamel (3). Bond strengths to primary enamel and permanent enamel were comparable for the Teeth Primer and 4-META/MMA-TBB resin adhesive system. Hosoya et al. (3) reported that bond strength to permanent enamel was greater after etching with $65 \%$ phosphoric acid than after priming with Teeth Primer.

Because Teeth Primer was developed as a self-etching primer, Nogawa et al. (4) compared the effectiveness of the primer and phosphoric acid as different types of etchant to be used together with 4-META/MMA-TBB resin. Their results (4) revealed that bond strength to human enamel treated with Teeth Primer was more durable than that etched with $40 \%$ or $65 \%$ phosphoric acid. Interestingly, the post-thermocycling reduction in bond strength was lower in the Teeth Primer group than in the acid-etched groups. 
Table 1 Materials assessed

\begin{tabular}{|c|c|c|c|}
\hline Material/ Trade name & Manufacturer & Lot & Composition (\%) \\
\hline \multicolumn{4}{|l|}{ Primer } \\
\hline Teeth Primer & Sun Medical Co., Ltd. Moriyama, Japan & ER2 & $\begin{array}{l}\text { 4-META } 10-30 \% \text {, sodium sulfite } 1-5 \% \text {, acetone } \\
20-40 \% \text {, water }\end{array}$ \\
\hline $\mathrm{Na}_{2} \mathrm{SO}_{3}$ solution & Sun Medical Co., Ltd. & 130718 & sodium sulfite $1-5 \%$, acetone $20-40 \%$, water \\
\hline 4-META solution & Sun Medical Co., Ltd. & 130718 & 4-META $10-30 \%$, acetone $20-40 \%$, water \\
\hline Acetone-water & Sun Medical Co., Ltd. & 130718 & acetone $20-40 \%$, water \\
\hline \multicolumn{4}{|l|}{ Etchant } \\
\hline K-Etchant Gel & Kuraray Noritake Dental Inc., Tokyo, Japan & 0495AA & phosphoric acid $35-45 \%$, colloidal silica \\
\hline \multicolumn{4}{|l|}{ Luting material } \\
\hline MMA & Tokyo Chemical Ind. Co., Ltd., Tokyo Japan & ZJ3WJIJ & MMA $99.8 \%$ \\
\hline Super-Bond Opaque powder & Sun Medical Co., Ltd. & EF1 & polyMMA, titanium oxide \\
\hline Super-Bond Catalyst & Sun Medical Co., Ltd. & VV61F & TBB, TBB-O, hydrocarbon \\
\hline
\end{tabular}

MMA, methyl methacrylate; 4-META, 4-methacryloxyethyl trimellitate anhydride; TBB, tri- $n$-butylborane; TBB-O, partially oxidized tri- $n$-butylborane

Although a number of mechanisms for bonding enamel and 4-META have been reported (12-17), there is limited information regarding the function of primer ingredients on the adhesive performance of MMA-TBB resin. The current study evaluated bonding durability between MMA-TBB resin without 4-META and human enamel after application of various surface preparations.

\section{Materials}

\section{Materials and Methods}

A self-etching primer (Teeth Primer), three experimental primers, and an etching gel (K-Etchant Gel, Kuraray Noritake Dental Inc., Tokyo, Japan) were used (Table 1). Teeth Primer consists of 4-META, a sodium sulfite $\left(\mathrm{Na}_{2} \mathrm{SO}_{3}\right)$ reducing agent, acetone, and water. To evaluate the effectiveness of the ingredients in Teeth Primer liquid, three primers were prepared: $\mathrm{Na}_{2} \mathrm{SO}_{3}$ solution, 4-META solution, and acetone-water.

A self-polymerizing acrylic resin initiated with TBB derivative was used as the luting agent. The TBB initiator and powder component of the material were the same as those in Super-Bond C\&B resin (Sun Medical Co., Ltd.). Reagent-grade MMA (Tokyo Chemical Industry Co., Ltd., Tokyo, Japan), which contains no functional monomers, was used as the monomer liquid in the MMA-TBB resin.

\section{Specimen preparation and bond strength testing}

A total of 66 non-carious, non-restored human molars were used as enamel specimens. After extraction, the teeth were cleaned under running water to remove blood and soft tissue remnants. The teeth were then stored in a $0.9 \mathrm{wt} \%$ isotonic sodium chloride solution for no longer than 1 month. Each tooth was mesiodistally sectioned into halves, using a low-speed diamond disk (IsoMET, Buehler, Lake Bluff, IL, USA). The halves were embedded in autopolymerizing acrylic resin, and the enamel surface was polished with a silicon carbide abrasive paper (WetorDry Tri-M-ite Sheet, 800 -grit, 3M, St. Paul, MN, USA) under running purified water. A piece of plastic tape with a circular hole, $3 \mathrm{~mm}$ in diameter, was placed on each enamel specimen to define the bonding area. The specimens were then randomly divided into six groups of 22 specimens.

Teeth Primer was applied to the enamel surface for 20 $\mathrm{s}$ and air-dried $(n=22)$. The $\mathrm{Na}_{2} \mathrm{SO}_{3}$ solution $(n=22)$, 4-META solution $(n=22)$, and acetone-water $(n=22)$ were applied in the same manner as the Teeth Primer. $\mathrm{K}$-Etchant Gel was applied to the enamel surface for 40 $\mathrm{s}$, washed with purified water, and air-dried $(n=22)$. The remaining specimens, i.e., those with no surface treatment of ground surfaces $(n=22)$, were washed with purified water and dried. A stainless steel ring (SUS303; inner diameter, $6 \mathrm{~mm}$; height, $2 \mathrm{~mm}$; wall thickness, $1 \mathrm{~mm}$ ) was positioned so that it surrounded the 3-mm-diameter circular hole and was then filled with the MMA-TBB resin, using a brush-dip technique.

After $30 \mathrm{~min}$, the bonded specimens were stored in $37^{\circ} \mathrm{C}$ purified water for $24 \mathrm{~h}$. This state was defined as 0 thermocycles, and six sets of 11 specimens were tested at this stage. The remaining six sets of 11 specimens were subjected to thermocycling for 20,000 cycles between $5^{\circ} \mathrm{C}$ and $55^{\circ} \mathrm{C}$ with $60 \mathrm{~s}$ dwell time for each water bath (Thermal Shock Tester TTS-1 LM, Thomas Kagaku, Tokyo, Japan). The specimens were then mounted in a testing jig on a mechanical testing device (Type 5567, Instron; Canton, MA, USA). Shearing load was applied at a crosshead speed of $0.5 \mathrm{~mm} / \mathrm{min}$. Shear bond strength was calculated as maximal fracture load divided by the circular bonded area.

After shear testing, the debonded surfaces were observed through an optical microscope $(\times 57$, SZX9, 
Table 2 Means, medians, and interquartile ranges (IQR) of shear bond strength (MPa)

\begin{tabular}{|c|c|c|c|c|c|c|c|c|}
\hline & \multicolumn{3}{|c|}{0 thermocycle $(n=11)$} & \multicolumn{4}{|c|}{20,000 thermocycles $(n=11)$} & \multirow{2}{*}{$\begin{array}{l}\text { Post-/Pre- } \\
\text { BS ratio (\%) }\end{array}$} \\
\hline & Mean & Median & IQR & Mean & Median & IQR & & \\
\hline Control & 3.4 & $3.2^{\mathrm{c}}$ & 0.8 & 4.7 & $4.6^{\mathrm{f}}$ & 0.6 & $S$ & 138.2 \\
\hline Teeth Primer & 31.7 & $32.2^{\mathrm{a}}$ & 2.2 & 17.7 & $17.1^{\mathrm{d}}$ & 3.5 & $S$ & 55.8 \\
\hline $\mathrm{Na}_{2} \mathrm{SO}_{3}$ & 3.4 & $3.4^{\mathrm{c}}$ & 0.9 & 4.3 & $4.2^{\mathrm{f}}$ & 0.5 & $S$ & 126.5 \\
\hline 4-META & 32.0 & $32.6^{\mathrm{a}}$ & 2.6 & 16.6 & $16.3^{\mathrm{d}}$ & 6.4 & $S$ & 51.9 \\
\hline Acetone-water & 2.7 & $2.8^{\mathrm{c}}$ & 1.0 & 4.4 & $4.4^{\mathrm{f}}$ & 0.7 & $S$ & 163.0 \\
\hline K-Etchant Gel & 14.9 & $14.0^{\mathrm{b}}$ & 2.9 & 11.1 & $10.8^{\mathrm{e}}$ & 3.3 & $S$ & 74.5 \\
\hline
\end{tabular}

Identical superscript letters indicate that the values are not significantly different $(P>0.05$; Steel-Dwass multiple comparison and Mann-Whitney $U$ test). $S$; Significant difference between pre- and post-thermocycling bond strengths $(P<0.05$; MannWhitney $U$ test); Post-/Pre- BS ratio, Post-/Pre-thermocycling bond strength ratio (\%)

Olympus Corp., Tokyo, Japan), and the cohesive failure ratio was analyzed and computed with image-analysis software (LMeye, Lasertec, Yokohama, Japan).

\section{Electron microscopic observation}

A thin layer of MMA-TBB resin was applied directly to the primed surface. After storage in purified water for $24 \mathrm{~h}$ at $37^{\circ} \mathrm{C}$, the bonded specimens were sectioned perpendicularly to the resin/enamel interface, using a low-speed saw (IsoMET, Buehler) under water coolant. The sectioned specimens were ground with a series of polishing papers (WetorDry Tri-M-ite Sheet, 800-, 1000-, 1200-, 1500-, and 2000-grit, 3M) under running purified water and polished using a non-woven pad (TexMet 1500, Buehler) and monocrystalline diamond suspensions (MetaDi, 3 and $1 \mu \mathrm{m}$, Buehler). The smeared layer and diamond suspensions were removed ultrasonically for 5 min in purified water. The polishing surfaces were etched with $10 \%$ orthophosphoric acid (P1745, Tokyo Chemical Industry Co., Ltd.) for $15 \mathrm{~s}$. The sectioned surfaces of the two bonded groups were etched with $6 \mathrm{~mol} / \mathrm{L}$ hydrochloric acid (HCl, Wako Pure Chemical Industries Ltd., Tokyo, Japan) for $25 \mathrm{~s}$. The specimens were then washed with purified water and dried for $24 \mathrm{~h}$ in a desiccator, after which they were sputter-coated with osmium for 60 s (Osmium Coater HPC-1SW, Vacuum Device Co., Ltd., Mito, Japan) and observed with a scanning electron microscope (SEM, S-4300, Hitachi High-Technologies Corp., Tokyo, Japan) operated at an accelerating voltage of $15 \mathrm{kV}$.

\section{Statistical analysis}

Shear bond strength was assessed by descriptive statistical analysis (mean, median, and interquartile range). All data were analyzed with the D'Agostino and Pearson omnibus normality test (GraphPad Prism 6, GraphPad software Inc., La Jolla, CA, USA). When the results showed a non-normal distribution in at least one category, the data were analyzed with the nonparametric KruskalWallis test (GraphPad Prism 6). On the basis of the results of that test, the Steel-Dwass multiple comparison test (Kyplot 5.0, KyensLab, Tokyo, Japan) was also performed to compare pre- or post-thermocycling condition in the six groups. The difference between pre- and post-thermocycling bond strengths for specimens in the same surface preparation group was analyzed with the Mann-Whitney $U$ test (GraphPad Prism 6.0). The threshold for statistical significance was set at $\alpha=0.05$.

\section{Shear bond strength testing}

\section{Results}

The D'Agostino and Pearson omnibus normality test revealed that shear bond strength test values were not normally distributed in the pre-thermocycling K-Etchant Gel group $(P=0.0013)$. The Kruskall-Wallis test and SteelDwass multiple comparison test were therefore used to evaluate shear bond strength results. The Kruskal-Wallis test showed that $\chi^{2}$ was 56.33 for the pre-thermocycling group and 53.73 for the post-thermocycling group $(P<$ 0.01 for pre- and post-thermocycling bond strengths). Therefore, the pre- and post-thermocycling results were analyzed independently with the Steel-Dwass nonparametric multiple comparison test.

Means, medians, and interquartile ranges for the shear bond strengths of the six conditions and statistical analyses are presented in Table 2. The 24-h median bond strengths without thermocycling ranged from 2.8 to 32.6 MPa. Pre-thermocycling bond strength was categorized into three groups (categories a-c). Median bond strength after 20,000 thermocycles ranged from 4.2 to 17.1 MPa. Post-thermocycling bond strength was also categorized into three groups (categories d-f). The Mann-Whitney $U$ test revealed that the bond strengths of Teeth Primer, 4-META solution, and K-Etchant Gel groups were lower after exposure to 20,000 thermocycles, whereas the bond strengths of the control, $\mathrm{Na}_{2} \mathrm{SO}_{3}$ solution, and 
Table 3 Results of failure mode analysis

\begin{tabular}{|c|c|c|c|c|c|c|}
\hline & \multicolumn{3}{|c|}{$\begin{array}{c}0 \text { thermocycle }(n=11) \\
\text { Cohesive failure ratio }(\%)\end{array}$} & \multicolumn{3}{|c|}{$\begin{array}{c}20,000 \text { thermocycles }(n=11) \\
\text { Cohesive failure ratio }(\%)\end{array}$} \\
\hline & Mean & Median & IQ) & Mean & Median & \%) \\
\hline Control & 7 & 6 & 4 & 3 & 3 & 2 \\
\hline Teeth Primer & 54 & 52 & 25 & 56 & 66 & 27 \\
\hline $\mathrm{Na}_{2} \mathrm{SO}_{3}$ & 8 & 9 & 5 & 4 & 4 & 3 \\
\hline 4-META & 52 & 56 & 17 & 51 & 50 & 10 \\
\hline Acetone-water & 6 & 6 & 5 & 5 & 5 & 5 \\
\hline K-Etchant Gel & 68 & 64 & 15 & 14 & 11 & 14 \\
\hline
\end{tabular}

IQR, interquartile range; Optical micrograph $\times 57$ and analyzing software; Cohesive failure ratio $(\%)=$ cohesive failure area $\left(\mathrm{mm}^{2}\right) \times 100 /$ bonded area $\left(\mathrm{mm}^{2}\right)$
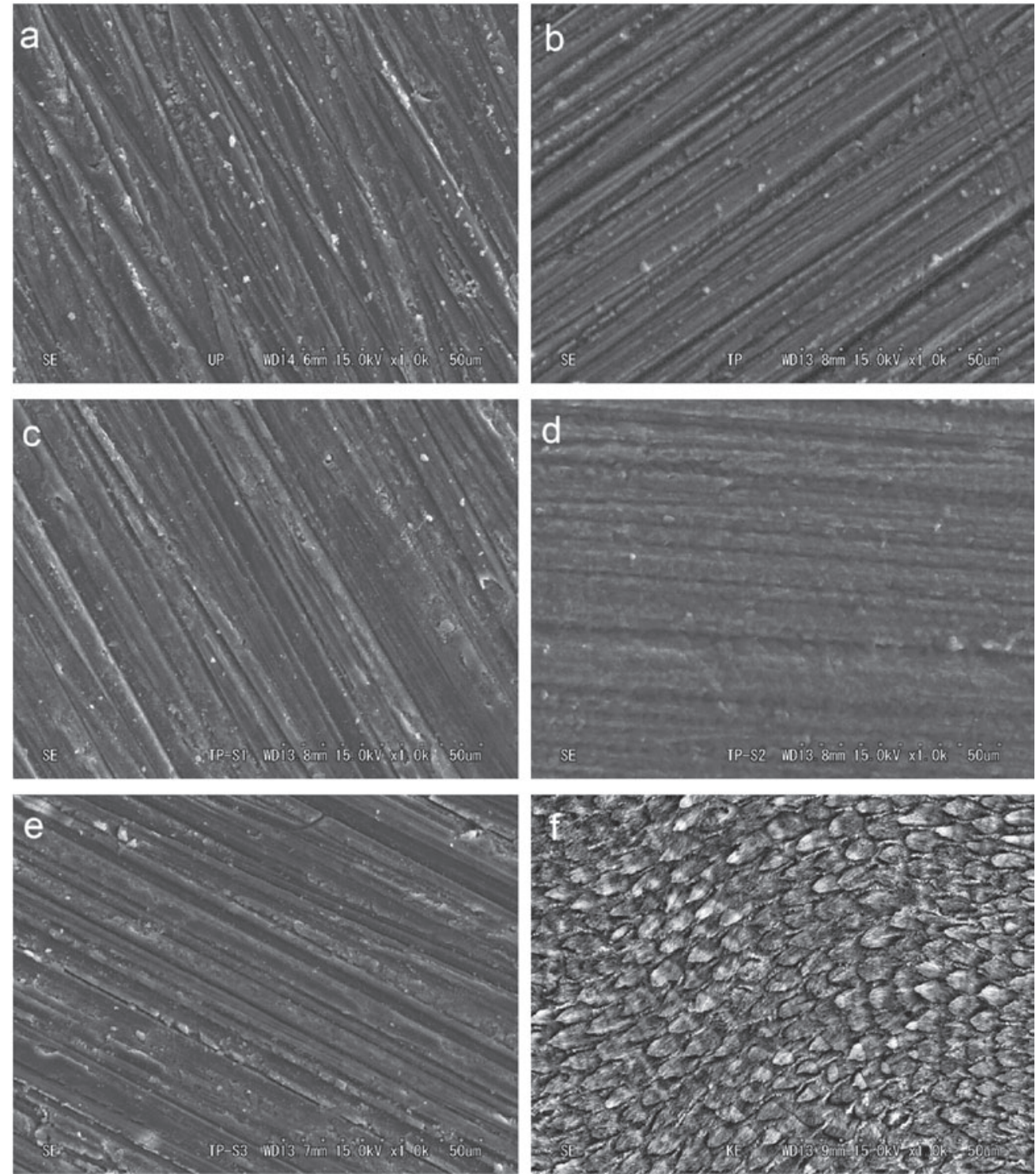

Fig. 1 Scanning electron micrographs of surface-prepared enamel surfaces.

a) ground with \#800 $\mathrm{SiC}$ abrasive paper (control); b) primed with Teeth Primer; c) primed with $\mathrm{Na}_{2} \mathrm{SO}_{3}$ solution; d) primed with 4-META solution; e) primed with acetone-water; f) etched with K-Etchant Gel (original magnification, $\times 1,000$ ) 

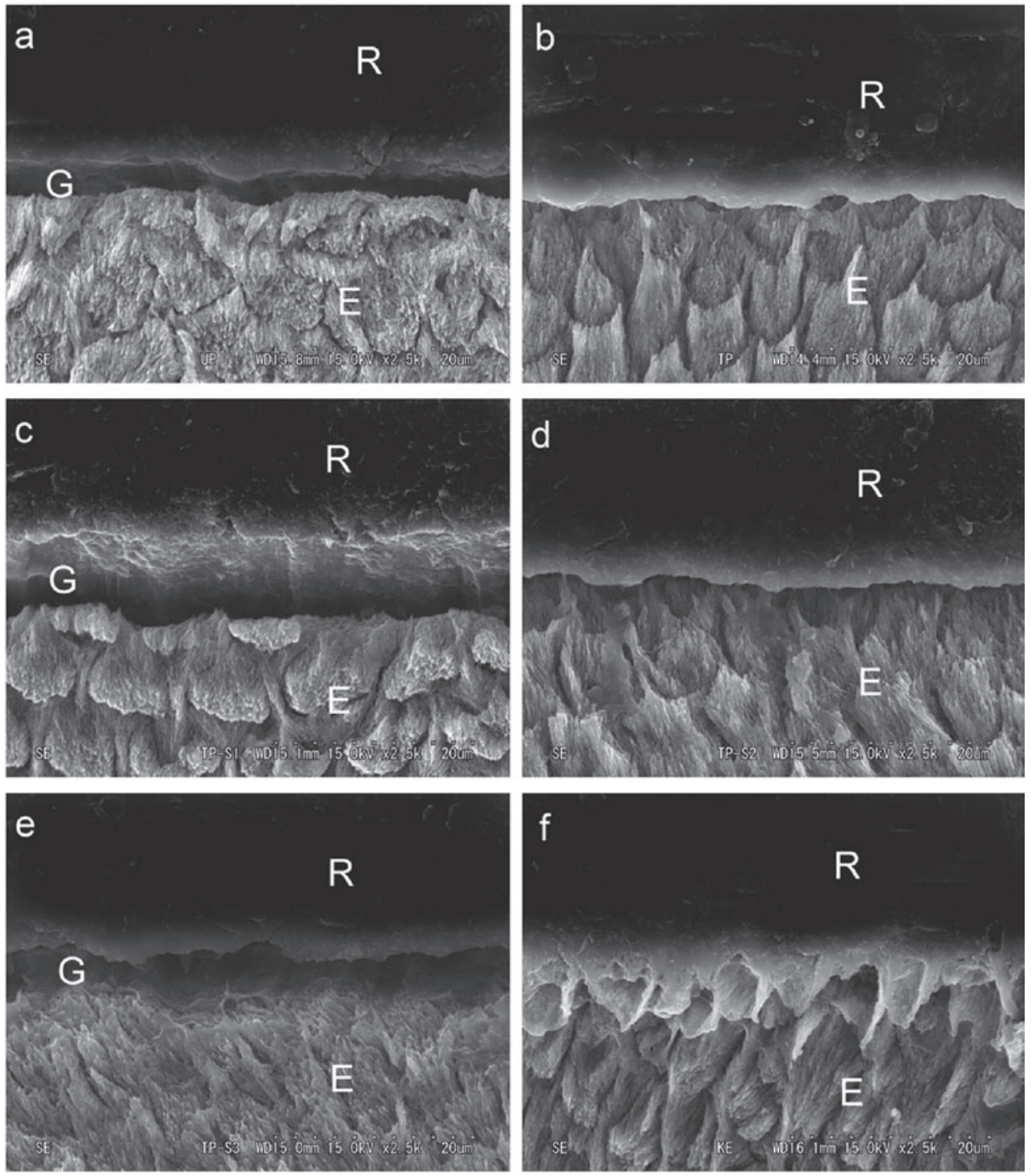

Fig. 2 Cross-sectional electron micrographs of bonded enamel specimens.

Sectioned surfaces were etched with $10 \%$ orthophosphoric acid for $15 \mathrm{~s}$. Original enamel surfaces before bonding: a) ground with \#800 $\mathrm{SiC}$ abrasive paper (control); b) primed with Teeth Primer; c) primed with $\mathrm{Na}_{2} \mathrm{SO}_{3}$ solution; d) primed with 4-META solution; e) primed with acetone-water; and f) etched with K-Etchant Gel (original magnification, $\times 2,500$ ). E, Enamel; R, MMA-TBB resin; and G: Gap

acetone-water groups were significantly higher. The ratio of post- to pre-thermocycling bond strength varied from $51.9 \%$ to $163.0 \%$.

\section{Failure mode analysis}

The results of failure mode analysis are summarized in Table 3. The 24-h median cohesive failure ratio without thermocycling ranged from $6 \%$ to $64 \%$, whereas the median cohesive failure ratio after 20,000 thermocycles ranged from $3 \%$ to $66 \%$. Although the post-thermocycling reduction in bond strength was more remarkable in the Teeth Primer and 4-META solution groups than in the etched group, the reduction in the cohesive failure ratio was apparent in the etched group: the mean ratio decreased from $68 \%$ to $14 \%$.

\section{Electron microscopic observation}

Figure 1 shows enamel surfaces after priming or etching. The characteristic scratches generated by abrasive paper are visible in Figs. 1a, 1b, 1c, and 1e. The 4-METAtreated enamel surface (Fig. 1d) had a somewhat different appearance as compared with the plain ground surface (Fig. 1a). The enamel surface etched with K-Etchant Gel (Fig. 1f) exhibited the typical etching pattern produced 

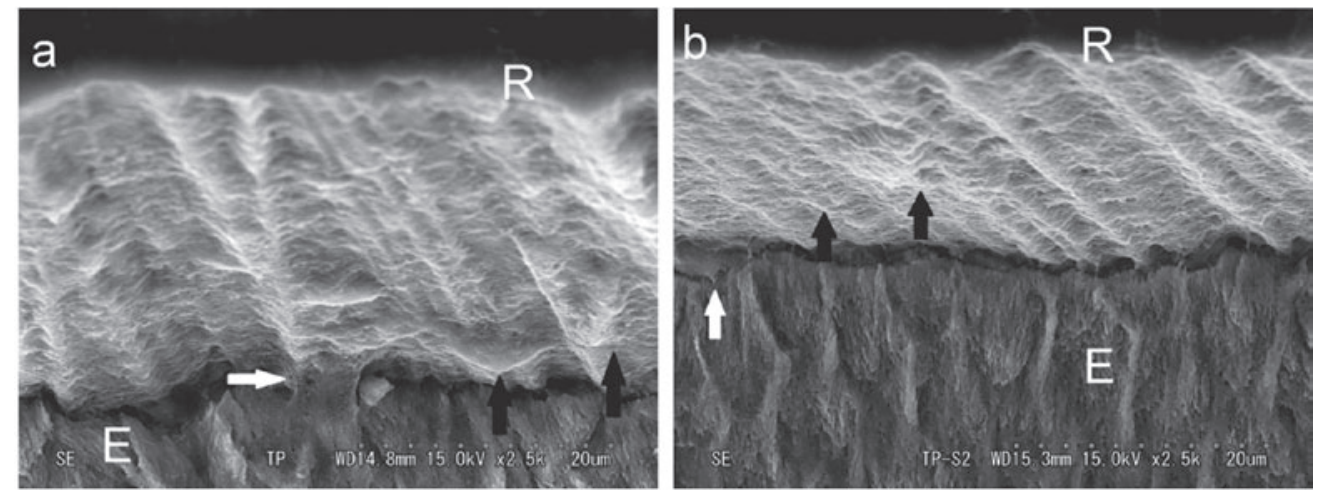

Fig. 3 Cross-sectional electron micrographs of bonded enamel specimens.

Sectioned surfaces were etched with $6 \mathrm{~mol} / \mathrm{L} \mathrm{HCl}$ for $25 \mathrm{~s}$. Original enamel surfaces before bonding: a) primed with Teeth Primer; and b) primed with 4-META solution (original magnification, $\times 2,500$ ). E, enamel; R, MMA-TBB resin; Black arrows, replicated self-etched enamel structure observed at the resin-side interface; White arrow, bonded enamel-resin structure

by phosphoric acid etchant.

Figures $2 \mathrm{a}-\mathrm{f}$ show enamel-resin interfaces in which the enamel was etched with phosphoric acid after bonding and halving. The unprimed group (Fig. 2a) and the two groups primed with $\mathrm{Na}_{2} \mathrm{SO}_{3}$ solution (Fig. $2 \mathrm{c}$ ) or acetonewater (Fig. 2e) had interfacial gaps between the resin and enamel. Gap formation was not observed in specimens primed with Teeth Primer (Fig. 2b) or 4-META solution (Fig. 2d) or in the etched and bonded group (Fig. 2f). In addition, multiple resin tags can be seen along the resinenamel interface in the etched and bonded specimen (Fig. 2f).

Figures $3 \mathrm{a}$ and $3 \mathrm{~b}$ show the enamel-resin interface etched with $\mathrm{HCl}(\mathrm{aq})$. The enamel surface was primed with Teeth Primer or 4-META solution before bonding with MMA-TBB resin. Both specimens showed no apparent debonding, and a roughened resin surface can be seen on both specimens.

Figure 4 shows debonded enamel surfaces of thermocycled specimens. Figures $4 \mathrm{a}, 4 \mathrm{c}$, and $4 \mathrm{e}$ show microscopic adhesive failure, similar to that seen on the pre-bonding surface. Resin remnants are present on surfaces originally treated with Teeth Primer (Fig. 4b), 4-META solution (Fig. 4d), and K-Etchant Gel (Fig. 4f).

\section{Discussion}

The current study evaluated the effects of phosphoric acid etching and the ingredients in Teeth Primer on the durability of bonding between human enamel and MMA-TBB resin without 4-META. This resin was used to exclude the adhesive characteristics of the luting agent. Pre- and post-thermocycling bond strengths in the three groups (unprimed control, $\mathrm{Na}_{2} \mathrm{SO}_{3}$ solution, and acetone-water) were less than $5 \mathrm{MPa}$ and comparable.
In addition, the ratio of post- to pre-thermocycling bond strength ranged from $126.5 \%$ to $163.0 \%$. The results from these three groups show that the effect of sodium sulfite was unremarkable. However, post-thermocycling bond strength in the three groups was greater than pre-thermocycling bond strength, although the cohesive failure ratio in the three groups was reduced after application of thermocycling. These results may be due to the fact that continuous polymerization of MMA monomer proceeds when there is a sufficient amount of TBB initiator, which was shown in a previous study of the polymerization kinetics of MMA-TBB resin (18). That report found that residual monomer in TBB-initiated resins was $4.5-11.6 \%$ after $30 \mathrm{~min}, 0.9-7.7 \%$ after $24 \mathrm{~h}$, and $0.8-7.1 \%$ after 4 weeks.

Pre- and post-thermocycling bond strengths in the Teeth Primer and 4-META solution groups were 32.2 $\mathrm{MPa}$ and $32.6 \mathrm{MPa}$, respectively, without thermocycling (category a) and $17.1 \mathrm{MPa}$ and $16.3 \mathrm{MPa}$ after thermocycling (category d). In contrast to the findings of a previous report (4), the reduction in bond strength was substantial in both groups. The past and present studies differed with regard to the use of a luting agent containing 4-META. It is not surprising that the presence of an acidic compound is not ideal for a redox initiation system. However, the presence of an acidic monomer in the luting system is indispensable for bonding to enamel. It is reasonable to assume that sodium sulfite in Teeth Primer functioned as a reducing agent and positively contributed to interfacial polymerization of 4-META/MMA-TBB resin $(4,14)$. This hypothesis suggests that there would be a significant difference between a control group and $\mathrm{Na}_{2} \mathrm{SO}_{3}$ solution group. However, no such difference was seen in the current study, perhaps because of the absence of an 

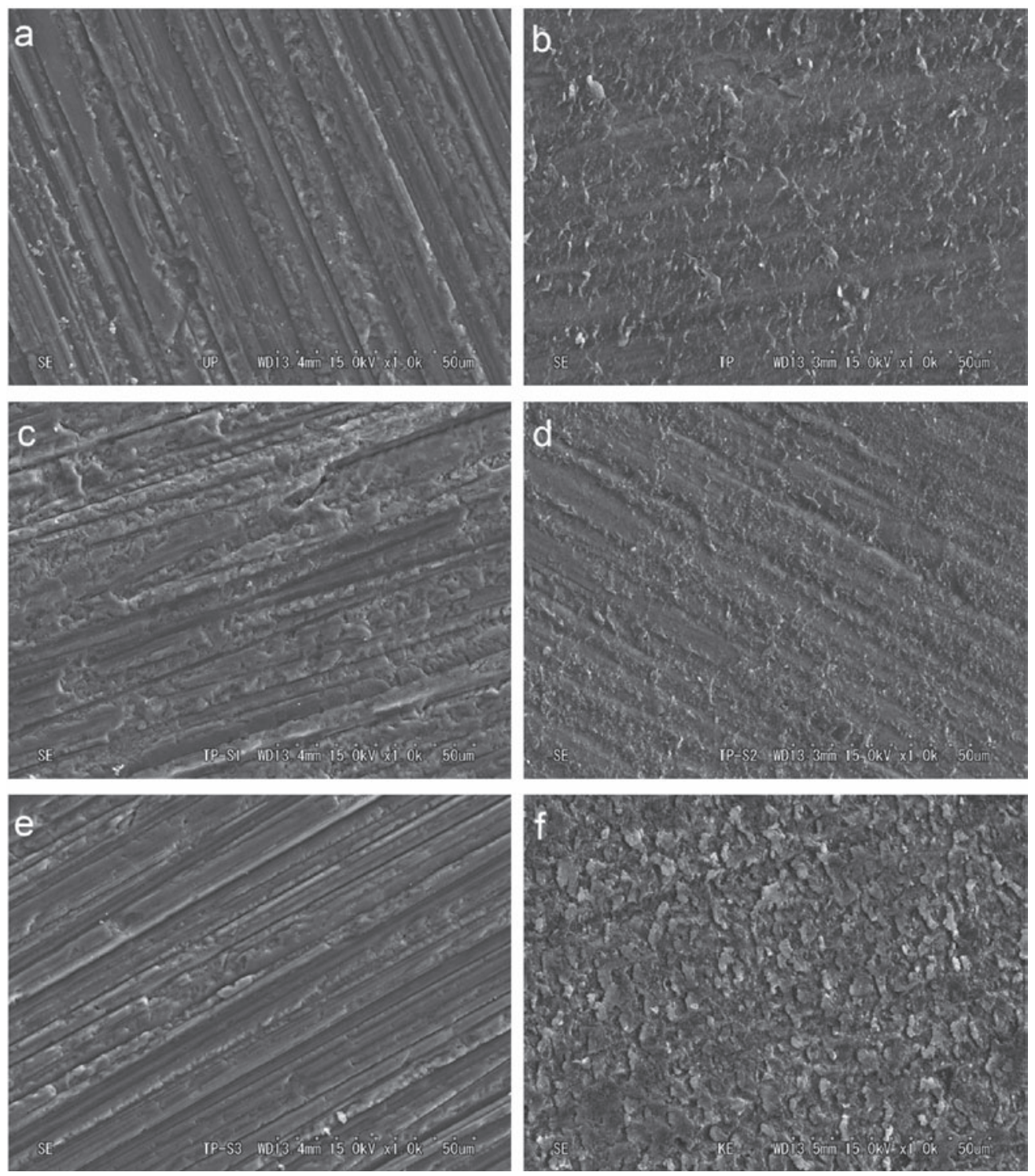

Fig. 4 Scanning electron micrographs of debonded enamel surfaces from representative thermocycled specimens.

Surface preparation before bonding: a) ground with \#800 SiC abrasive paper (control); b) primed with Teeth Primer; c) primed with $\mathrm{Na}_{2} \mathrm{SO}_{3}$ solution; d) primed with 4-META solution; e) primed with acetone-water; and f) etched with K-Etchant Gel (original magnification, $\times 1,000$ )

acidic compound in the luting agent used in this study. We speculate that a reducing agent such as sodium sulfite enhances the postpolymerization mechanical properties of TBB-initiated resin at the enamel-resin interface, in the absence of an acidic compound. However, the effect of the reducing agent is diminished in the presence of a carboxylic adhesive monomer. Instead, the acidic monomer considerably enhanced chemical bonding between enamel and the TBB-initiated resin, because of the effect of hydrolyzed 4-META.

The results of bond strength testing and scanning electron micrographs suggest that 4-META functioned as a self-etchant (Figs. 1a and d). With respect to 4-META monomer, the priming system (4-META solution + MMA-TBB resin) had greater post-thermocycling bond strength (16.3 MPa; Table 2) than did the 4-META/ MMA-TBB self-adhesive system (4.6 MPa) (4). The results strongly suggest that presence of adhesive functional monomer is indispensable at the adhesive interface rather than internal structure of the polymerizing luting agent $(12,15)$. Figure 3 clearly shows a roughened relief pattern in the enamel (black arrows), which was probably generated from the self-etching effect of 4-META. Additionally, the absence of a wide gap between enamel and resin (white arrows) suggests that the 4-META primers had a bonding effect. Moreover, the bonding 
effect of 4-META is shown in a debonded surface (Fig. 4) exhibiting typical adhesive-cohesive combined failure at the bonded interface.

Among the three groups-Teeth Primer, 4-META solution, and phosphoric acid etching - the reduction in bond strength after thermocycling was minimal in the etched group (post-/pre-bond strength ratio, 74.5\%). As shown in Fig. 2f, bonding to etched enamel substantially derives from mechanical interlocking (19-21) between the etched enamel and penetrated MMA-TBB resin $(1,4)$.

Within the limitations of the current experimental setting, it can be concluded that etching enamel with $40 \%$ phosphoric acid is a reliable surface preparation for bonding enamel with MMA-TBB resin. Application of 4-META solution resulted in slight etching of the enamel surface. Priming with 4-META solution considerably enhanced bond strength between enamel and MMA-TBB resin. Sodium sulfite had an unremarkable effect on enamel bonding in the present bonding systems.

\section{Acknowledgments/ Ethics/ COI}

This work was supported in part by a Grant-in-Aid for Scientific Research (C) 24592934 (2012-2014) from the Japan Society for the Promotion of Science (JSPS), by a Grant from the Dental Research Center, Nihon University School of Dentistry (2014), and by Special Research Grants for the Development of Distinctive Education from the Promotion and Mutual Aid Corporation for Private Schools of Japan (2012 and 2014). This study was approved by the Ethical Committee of Nihon University School of Dentistry (2014-4). Conflicts of interest: None declared.

\section{References}

1. Nakabayashi N, Masuhara E (1978) Development of adhesive pit and fissure sealants using a MMA resin initiated by a tri-nbutyl borane derivative. J Biomed Mater Res 12, 149-165.

2. Iijima M, Ito S, Nakagaki S, Muguruma T, Kohda N, Saito T et al. (2013) Effects of the addition of fluoride to a 4-META/ MMA-TBB-based resin adhesive on fluoride release, acid resistance of enamel and shear bond strength in vitro. Dent Mater J 32, 156-164.

3. Hosoya Y Tay FR (2014) Bonding ability of 4-META selfetching primer used with 4-META/MMA-TBB resin to enamel and dentine: primary vs permanent teeth. J Dent 42 , 425-431.

4. Nogawa H, Koizumi H, Saiki O, Hiraba H, Nakamura M, Matsumura H (2015) Effect of a self-etching primer and phosphoric acid etching on the bond strength of 4-META/ MMA-TBB resin to human enamel. Dent Mater J 34, (in press).

5. Nakabayashi N, Kojima K, Masuhara E (1982) The promotion of adhesion by the infiltration of monomers into tooth substrates. J Biomed Mater Res 16, 265-273.

6. Tanaka T, Fujiyama E, Shimizu H, Takaki A, Atsuta M (1986)
Surface treatment of nonprecious alloys for adhesion-fixed partial dentures. J Prosthet Dent 55, 456-462.

7. Kakino K, Endo K, Hashimoto M, Furuta K, Ohno H (2014) Visualization study on distortion of a metal frame by polymerization shrinkage and thermal contraction of resin. Dent Mater J 33, 118-124.

8. Imai H, Koizumi H, Shimoe S, Hirata I, Matsumura H, Nikawa H (2014) Effect of thione primers on adhesive bonding between an indirect composite material and Ag-PdCu-Au alloy. Dent Mater J 33, 681-688.

9. Matsumura H, Kawahara M, Tanaka T, Atsuta M (1989) A new porcelain repair system with a silane coupler, ferric chloride, and adhesive opaque resin. J Dent Res 68, 813-818.

10. Miyazaki T, Nakamura T, Matsumura H, Ban S, Kobayashi $\mathrm{T}$ (2013) Current status of zirconia restoration. J Prosthodont Res 57, 236-261.

11. Tanimura R, Suzuki S (2014) In vitro evaluation of a modified 4-META/MMA-TBB resin for filling access holes of screw-retained implant prostheses. J Biomed Mater Res B Appl Biomater 2014 Sep 16. doi: 10.1002/jbm.b.33289.

12. Imai $Y$, Kadoma $Y$, Kojima K, Akimoto T, Ikakura K, Ohta $\mathrm{T}$ (1991) Importance of polymerization initiator systems and interfacial initiation of polymerization in adhesive bonding of resin to dentin. J Dent Res 70, 1088-1091.

13. Ozaki M, Suzuki M, Itoh K, Wakumoto S (1991) LaserRaman spectroscopic study of the adhesive interface between 4-MET/MMA-TBB resin and hydroxyapatite or bovine enamel. Dent Mater J 10, 105-120.

14. Okamoto Y, Takahata K, Saeki K (1998) Studies on the behavior of partially oxidized tributylborane as a radical initiator for methyl methacrylate (MMA) polymerization. Chem Lett 27, 1247-1248.

15. Fujisawa S, Ito S (1999) $1 \mathrm{H}-\mathrm{NMR}$ studies of the interaction of dental adhesive monomer, 4-META with calcium. Dent Mater J 18, 54-62.

16. Nagakane K, Yoshida Y, Hirata I, Fukuda R, Nakayama Y, Shirai K et al. (2006) Analysis of chemical interaction of 4-MET with hydroxyapatite using XPS. Dent Mater J 25, 645-649.

17. Iwai H, Fujita K, Iwai H, Ikemi $\mathrm{T}$, Goto $\mathrm{H}$, Aida $\mathrm{M}$ et al. (2013) Development of MDP-based one-step self-etch adhesive--effect of additional 4-META on bonding performance. Dent Mater J 32, 1-9.

18. Kwon TY, Imai Y (2004) Polymerization characteristics of ethyl methacrylate-based resin initiated by TBB. Dent Mater J 23, 161-165.

19. Månson-Rahemtulla B, Retief DH, Jamison HC (1984) Effect of concentrations of phosphoric acid on enamel dissolution. $\mathrm{J}$ Prosthet Dent 51, 495-498.

20. Zidan O, Hill G (1986) Phosphoric acid concentration: enamel surface loss and bonding strength. J Prosthet Dent 55, 388-392.

21. Zhu JJ, Tang AT, Matinlinna JP, Hagg U (2014) Acid etching of human enamel in clinical applications: a systematic review. J Prosthet Dent 112, 122-135. 